\title{
A participação das crianças no jornalismo infantojuvenil português e brasileiro'
}

\section{The participation of children in the journalism made for them in Brazil and Portugal}

Juliana Doretto

Centro Universitário Fiam-Faam

<jdoretto@gmail.com>

\section{RESUMO}

Este trabalho, parte de tese de doutoramento, se concentra na participação das crianças no jornalismo infantil. Buckingham (2009) entende que os meninos e meninas devem exercer os seus direitos de participação, estabelecidos na Convenção sobre os Direitos da Criança (1989), também na área da produção midiática: segundo ele, as novas formas de comunicação on-line que as crianças têm à sua disposição são possíveis formas de assegurar esse direito. Mas as crianças as utilizam para interagir com os jornalistas que escrevem para elas? Para responder a essa questão, entrevistamos 50 crianças de nove a 16 anos de idade, em Portugal e no Brasil. O trabalho mostrou que, para que haja participação, é preciso que as crianças se sintam motivadas a acompanhar com frequência os veículos infantis - o que está atrelado à mediação adulta e à temática abordada pelas publicações. Além disso, dois obstáculos aparecem: a ausência de resposta por parte dos produtores de informação e a preocupação das crianças em expor-se.

Palavras-chave: Crianças. Participação. Jornalismo infantojuvenil.

\begin{abstract}
This work, part of a thesis, focuses on the children's participation in the journalism done for them. Buckingham (2009) understands that children must exercise their rights of participation - established by the Convention on the Rights of the Child (1989) - also in the area of media's production. The participation channels offered by the media, through the internet, are possible ways of ensuring the right defended by Buckingham. But children have been using the new digital forms of participation to communicate with journalists who write for them? To answer these questions, we interviewed 50 children from 9 to 16 years old Brazil and Portugal. The study showed that, for participation happens, it is necessary that children feel motivated to follow often children's media which is linked to adult mediation and the stories' themes presented by the publications. In addition, two obstacles appear: the lack of response from the producers of information and the concern of children in exposing themselves.
\end{abstract}

Keywords: Children. Participation. Journalism made for children.

\section{INTRODUÇÃO}

"É uma consequência do formato do ovário e do que seria a organização dos óvulos em cada uma das cinco câmeras ou lóbulos onde ficam abrigados." Esse texto responde à seguinte pergunta: "Por que a carambola tem formato de estrela?". Se essa resposta estivesse num magazine de divulgação científica voltado para adultos já seria difícil compreender o que significam as câmeras

1 Versão preliminar deste texto foi apresentada ao Grupo de Trabalho Recepção: processos de interpretação, uso e consumo midiáticos do XXV Encontro Anual da Compós, na Universidade Federal de Goiás, Goiânia, de 7 a 10 de junho de 2016. Esta pesquisa foi financiada pela Capes. 
ou os lóbulos da fruta. Talvez coubesse para uma publicação que abordasse a biologia e fosse destinada para estudantes ou profissionais da área. Mas a frase foi divulgada no dia 12 de maio de 2015 na seção "Curiosidades" do site da revista brasileira Recreio (2015), cujo público-alvo são crianças de seis a 11 anos. A questão que surge aqui é por que o magazine escreve um texto tão cifrado para um leitorado que ainda se inicia no mundo letrado e que também começa os estudos das ciências naturais. Disfunções como essa demonstram como é arenoso esse campo especializado do jornalismo, que deve responder a uma audiência com especificidades cognitivas e vivências tão diferentes das dos adultos (e em algumas áreas tão iguais, o que nem sempre é compreendido pelos já crescidos). É a essa produção jornalística por vezes nebulosa que vamos dedicar este texto.

Para entender o jornalismo feito para as crianças, temos de pensá-lo como algo que vai além do tipo de produção jornalística que tem como público leitor as crianças, mas que busca, ao falar diretamente para elas (com a aprovação dos pais, já que são eles que normalmente compram ou entregam esses produtos aos filhos), traçar padrões e modelos para a parcela da infância contemporânea ${ }^{2}$ que deseja atingir: as áreas sobre as quais as crianças devem se informar, do que deveriam falar, o que devem ler e ouvir, como podem se divertir - e, mais além, como o produto feito para elas deve ser apresentado, de que material deve ser confeccionado e como deve ser divulgado (Kress; Leeuwen, 2001). E isso, é claro, influencia o modo como a instituição infância é entendida de forma geral na sociedade; e pode, inclusive, modificar as concepções que as próprias crianças leitoras têm do que é ser criança na sociedade contemporânea. Daí a importância de os meninos e meninas conseguirem influenciar a construção desse discurso.

Nesse sentido, há uma esfera de garantias legais, expressas na Convenção sobre os Direitos da Criança da Organização das Nações Unidas, de 1989, que asseguram a participação dos garotos e garotas na vida cultural. Para David Buckingham (2009), no entanto, esses direitos também devem ser relacionados à mídia, no sentido de que as crianças têm de falar tanto aos produtores quanto aos reguladores midiáticos, influenciando as decisões tomadas na área. Isso seria ainda uma forma de expansão dos direitos políticos das crianças, não manifestados na Convenção. Além disso, o pesquisador inglês defende o

2 Em todo este trabalho, não entendemos "infância" como uma classe etária, mas seguimos a visão dos autores da "nova sociologia da infância". Segundo eles, a "infância", enquanto instituição da sociedade, não é determinada apenas por questões biológicas (o desenvolvimento físico e cognitivo de fato existe), mas é principalmente construída por meio de discursos (entre eles, o jornalístico), ações e valores dos atores que disputam espaço no jogo social (Livingstone; Drotner, 2008). 
estabelecimento de uma outra garantia legal, relacionada a essa participação, mas ainda não expressa na Convenção: o direito à representação (seja fabricar a própria ou criticar às já oferecidas pela mídia).

Entendemos que, por meio dos novos canais digitais, multiplicaram-se as oportunidades de as crianças criarem e divulgarem seus próprios conteúdos (ou suas próprias representações) mas também aumentaram as chances de elas se comunicarem com as instâncias midiáticas que produzem outras imagens das infâncias contemporâneas ${ }^{3}$. Entre elas, destacam-se os veículos jornalísticos infantojuvenis, e, segundo nosso entendimento, quando os meninos e meninas tentam intervir na produção do jornalismo que os têm como público-alvo, eles também reclamariam por representações mais próximas do que eles entendem estar vivendo, ou seja, "ser criança" em nossos dias.

No entanto, Dijck (2013) mostra que, se, na primeira década do século 21, essa tecnologia prometia conectividade e protagonismo dos usuários, por meio de plataformas sociais, hoje essas estruturas não apenas acabaram concentradas (propriedades de algumas poucas corporações econômicas) mas também se revelaram concentradoras (poucas plataformas hoje congregam milhões de usuários, em sistemas de funcionamento cada vez mais fechados; ou seja, o utilizador pode criar pouco; deve seguir modos fixos de publicação). Além disso, o discurso democrático e igualitário da internet participativa não se sustentou: os que são mais populares, dentro da rede ou fora dela, "valem mais" para essas plataformas, pois conseguem gerar mais lucros, conquistar mais "seguidores" (o que significa mais audiência), influenciar comportamentos de consumo. Ainda que se possa dizer que os usuários "comuns" podem modificar as plataformas com estratégias conscientes de popularização de tópicos, o poder de influência entre proprietários e utilizadores é obviamente desigual, e é necessário que seja assim para que a estrutura das mídias sociais funcione.

A sociabilidade on-line precisa de influenciadores tanto quanto de seguidores, de personalidades tanto quanto de admiradores, de criadores tanto quanto de consumidores, de profissionais tanto quanto de amadores, de editores tanto quanto de leitores (Dijck, 2013, p. 159).

3 Essas "infâncias" se diferem da instituição social "infância": referimo-nos aqui aos diversos contextos socioeconômicos e culturais em que os meninos e meninas são crianças hoje. 


\section{PROCEDIMENTOS METODOLÓGICOS}

Conforme exposto acima este trabalho parte de nossa tese de doutoramento e defende que, ao buscar influenciar os veículos jornalísticos produzidos para o público infantil, o que pode ser facilitado pelas novas tecnologias de comunicação e informação, as crianças poderiam reclamar por melhores representações na mídia a elas destinada. Para isso, nossa investigação questionou se, em primeiro lugar, as crianças de fato aproveitam essas novas possibilidades de participação e, quando o fazem, se estão interessadas em aperfeiçoar as representações da(s) infância(s) no jornalismo infantojuvenil.

Para responder às perguntas acima, era preciso fazer escolhas pragmáticas de pesquisa. O Brasil, nosso país de origem e cujos recursos públicos financiaram nossa investigação, deveria estar incluído, assim como Portugal, nação que nos recebeu para o desenvolvimento da investigação. Optamos por veículos impressos, já que no Brasil não há produto jornalístico audiovisual para as crianças e não nos interessam formatos apenas on-line, pois queríamos entender também a relação entre os canais digitais e os meios impressos. Em Portugal, escolhemos a única revista para crianças publicada na mídia nacional, a Visão Júnior; no Brasil, após tentativas falhadas tanto por encerramento de produtos quanto por negativas da redação de acesso a materiais, conseguimos a colaboração da Ciência Hoje das Crianças, ou CHC.

A partir dessa escolha, entrevistas de profundidade e semiestruturadas foram feitas com 26 crianças, entre nove e 16 anos: 13 em Portugal e 13 no Brasil. Entendemos aqui a entrevista semiestruturada conforme proposto por Ghiglione e Matalon (2005): blocos temáticos predefinidos (e não perguntas fechadas), cuja ordem pode ser modificada se o entrevistado se adiantar a um assunto tencionado. Foram realizados ainda quatro grupos de foco, na mesma faixa etária, em cada um dos dois países, envolvendo outras 25 crianças. 0 objetivo foi conversar tanto com meninos e meninas que pertencem à faixa do público-alvo dos dois magazines quanto com adolescentes que pudessem ter sido leitores das revistas (e/ou de outros produtos infantojuvenis) ou que nos relatassem como foi sua experiência, na infância, com veículos jornalísticos destinados a eles. Nosso propósito em conversar não só com crianças leitoras dos veículos infantis, mas também com não leitoras seria o de analisar como se davam essas diferentes relações com o jornalismo infantojuvenil. Afinal, "não é evidente que a recusa da audiência em apenas se engajar com um texto de modo suficiente para fazer qualquer decodificação dele (...) é uma leitura menos opositora do que uma que está pelo menos suficientemente engajada" (Morley, 2006, p. 13). 
A escolha dos nove anos como idade mínima deu-se em virtude de esta ser uma idade que: abarca o público-alvo dos dois magazines; e, em geral, a criança nessa etapa já consegue ler e escrever com alguma destreza. Os entrevistados acima dos 14 anos eram os que já não faziam parte do público leitor pretendido pelos magazines e poderiam nos contar como era seu envolvimento com as notícias quando crianças (e sua possível participação em alguns veículos infantis) - oferecendo análises diferentes das feitas pelas que hoje são crianças, tendo em vista que contam com diferentes experiências culturais e com recursos intelectuais mais sofisticados. Eventualmente, eles também poderiam relatar diferenças no relacionamento atual que têm com o jornalismo por terem sido ou não crianças leitoras de veículos infantojuvenis. $O$ limite de 16 anos foi estabelecido para que houvesse uma distância temporal maior entre um possível acompanhamento prévio do jornalismo para crianças, cujos produtos em geral focam até os 14 anos, e a idade atual.

Para as entrevistas, conseguimos uma amostra de conveniência, e essas referências orientaram também a escolha das cidades, tanto as capitais quanto as de zonas interiores, em que a pesquisa se deu. No país europeu, os entrevistados eram moradores da cidade de Lisboa e dos seus arredores urbanos (concelho de Sintra), ou da região de Estremoz (cidade com cerca de 14 mil habitantes e a aproximadamente $171 \mathrm{~km}$ da capital). No Brasil, as crianças e jovens eram moradores das regiões metropolitanas de São Paulo e Rio de Janeiro, ou de Marília (cidade com cerca de 200 mil habitantes e a cerca de 450 km de São Paulo).

\section{O JORNALISMO INFANTIL SEGUNDO SEU PÚBLICO}

Como nos interessa saber se a possibilidade de acesso ubíquo à internet, por meio de aparatos móveis, vem mudando as relações descritas acima, todos os entrevistados tinham acesso a meios móveis de comunicação, como celulares, smartphones ou tablets (de sua posse ou de outros familiares), ainda que o uso fosse diferente, o que fez que as desigualdades socioeconômicas fossem aqui pouco pronunciadas: tratava-se de crianças e jovens de classe média ou média alta, com pais com no mínimo ensino fundamental completo (a maioria, no entanto, tinha finalizado a educação secundária ou o superior).

Comecemos pelos atuais e possíveis leitores das revistas e olhemos, num primeiro momento, para os mais novos, crianças entre nove e 11 anos. Em Portugal, dos cinco entrevistados com essas idades, apenas uma menina, 
Paula ${ }^{4}$, de dez anos, moradora de Lisboa, cujos pais têm ensino superior (um deles, inclusive, é jornalista), se disse uma leitora mais habitual:

Pesquisadora: Conhece a Visão Júnior?

- Conheço. Sim, eu leio.

Pesquisadora: Você gosta?

- Ela ensina muita coisa, ensina a ser educado com os mais velhos, com os idosos, a ajudá-los...5

Os meninos, de nove e 11 anos, disseram não conhecer a revista, mas as outras meninas, com as mesmas idades, relataram estar familiarizadas com a publicação, ainda que a leitura que façam dela seja escassa ou mesmo inexistente. Nenhuma criança mencionou o telejornal Diário XS, que é voltado para o público infantil e exibido no canal público RTP.

Pesquisadora: Você conhece alguma revista ou jornal para criança?

- A revista Júnior.

Pesquisadora: Você gosta, você lê?

- Eu... eu acho que só li uma, um dia.

Pesquisadora: E não gostou muito?

- Nunca foi..., não foi bem o meu interesse, mas vá... é engraçado, estavam lá coisas até engraçadas, mas eu... aquilo não... não comprei a revista. Foi uma professora minha da antiga escola que emprestou a toda a gente na minha sala.

Pesquisadora: Mas só foi uma vez... não pediu para sua mãe comprar outras?

- Não, foi só uma vez. (Mônica, 9 anos, Estremoz). ${ }^{6}$

Pesquisadora: Conhece a Visão Júnior? Sabe aquela revista para crianças?

- Sim, sim.

Pesquisadora: Você conhece?

- Sim.

Pesquisadora: Já leu?

- Não.

Pesquisadora: Não se interessa?

4 Todos os nomes são fictícios.

5 Entrevista concedida por PAULA. Entrevista 1. (5 abr. 2014). Entrevistadora: Juliana Doretto. Lisboa (Portugal), 2014.

6 Entrevista concedida por MÔNICA. Entrevista 2. (8 fev. 2014). Entrevistadora: Juliana Doretto. Estremoz (Portugal), 2014. 
- Não.

Pesquisadora: Nem na biblioteca da escola leu?

— Não... na biblioteca da escola há só mesmo os computadores, depois há livros... (Fátima, 10 anos, Lisboa). ${ }^{7}$

No Brasil, com a maior oferta de veículos de informação para crianças, os relatos de leitura desses produtos jornalísticos foram mais frequentes do que o encontrado em Portugal, ainda que as crianças nem sempre acompanhem as publicações com constância. Entre os meninos, o distanciamento em relação a esses veículos pareceu ainda maior: Mário, de 11 anos, de São Paulo, disse que uma vez viu a Folhinha, suplemento infantil do jornal Folha de S. Paulo, mas achou "muito podre" dez anos, de São Paulo, não disse que já a tinha lido; ou melhor, contou que não tinha brincado com ela, pois a publicação é sempre lembrada por seus jogos e pelos brinquedos que vêm como brinde:

Pesquisadora: Você já leu algum jornal ou revista para criança?

- A Recreio.

Pesquisadora: Você assinava? Via na biblioteca da escola? Comprava?

— Já comprei umas duas vezes. Umas duas que tinham brinquedo.

Pesquisadora: Você gostou?

— Tem uma parte de piada, que fala de uns filmes, tem parte que fala de jogos. Tem umas atividades lá, que tem de caçar umas coisas.

Pesquisadora: Você esperava mais?

— Eu achei legal. (Laura, 10 anos, Marília). ${ }^{9}$

A escola foi o canal para que Cristina, nove anos, de Marília, conhecesse a Ciência Hoje das Crianças. Isso ocorreu por meio de atividades propostas pelos docentes:

Pesquisadora: Você já leu alguma revista ou jornal para criança?

7 Entrevista concedida por FÁTIMA. Entrevista 3. (15 fev. 2014). Entrevistadora: Juliana Doretto. Lisboa (Portugal), 2014.

8 Entrevista concedida por MÁRIO. Entrevista 4. (8 set. 2014). Entrevistadora: Juliana Doretto. São Paulo (Brasil), 2014.

9 Entrevista concedida por LAURA. Entrevista 5. (19 set. 2014). Entrevistadora: Juliana Doretto. Marília (SP, Brasil), 2014. 
- Na escola tem a revista Recreio, e a "Ciências Hoje". E aí tem matéria sobre ela e a gente tem que ler.

Pesquisadora: A professora pede?

- Na sala, tem tipo uma estante, que tem gibi (histórias em quadrinhos), umas caixas de livros. Tem hora que a professora deixa a gente pegar livro, revista para ler. Pego mais livro e a Recreio eu pego para jogar com as minhas amigas. Tem um joguinho "pra" ver onde "tão" as coisas.

Pesquisadora: Você gosta?

— Eu acho que é legal. Tem vários jogos e coisa sobre animal.

Pesquisadora: Você gosta de animais?

— Eu gosto de animal. Não tanto de ler coisas sobre animal. (...)

Pesquisadora: E a Ciência Hoje das Crianças?

— Eu só leio"pra” matéria da escola mesmo (...) Por causa que é de ciências. Eu não gosto muito (de ciências). ${ }^{10}$

O ambiente escolar foi também responsável pelo contato com o Joca, jornal cujo objetivo é explicar atualidades noticiosas para as crianças. Para garotos de 11 e 12 anos, ouvidos durante um grupo focal em São Paulo, esse produto falha ao ser muito aborrecido e circunspecto.

Lucas: Já li acho que Folhinha, mas só foi uma vez.

Pesquisadora: "Tava" legal?

Lucas: É... Porque as notícias não "tavam" tão interessantes quanto as de adultos.

Pesquisadora: Notícia para adulto é mais legal do que para criança?

Vários meninos: Sim.

Jorge: Por exemplo, o Joca vai lá e faz assim. Por exemplo, "tá" só nome é diferente, e o resto é tudo para adulto. O nome está "Jornalzinho para criança". Daí o resto é cópia do jornal normal.

Pesquisadora: Isso é bom ou ruim?

Jorge: Mais ou menos. (...)

Pesquisadora: Se fosse diferente, deveria ser diferente como?

Jorge: Um pouquinho mais engraçado, para eu entender mais.

Renato: Notícia para criança diz assim: "O parquinho..."11

10 Entrevista concedida por CRISTINA. Entrevista 6. (18 set. 2014). Entrevistadora: Juliana Doretto. Marília (SP, Brasil), 2014.

11 Entrevistas concedidas por LUCAS, JORGE e RENATO. Grupo focal 1. (1 out. 2014). Entrevistadora: Juliana Doretto. São Paulo (Brasil), 2014. 
As falas transcritas acima demonstram que, para os garotos, as notícias no jornalismo infantil reduzem o conhecimento vocabular e, consequentemente, a capacidade de entendimento das crianças (ao usar diminutivos, como "Jornalzinho"; "O parquinho...") e sua gama de interesses, que podem ser tão variados quanto os dos adultos ("as notícias não 'tavam' tão interessantes quanto as de adultos") No entanto, demonstram que o jornalismo para crianças não pode ser uma cópia dos adultos: é preciso redigir textos com mais humor.

Numa faixa posterior, entre os 12 e 14 anos, nota-se que, em Portugal, a Visão Júnior era conhecida por todos os entrevistados, em algum grau, enquanto no Brasil todos citaram ter lido algum suplemento ou revista para crianças (ainda que com frequência confundissem o Estadinho e a Folhinha, cadernos infantis dos dois principais jornais do Estado de São Paulo). Nos dois países, nas entrevistas individuais entre os que tinham 12 ou 13 anos, destacouse nas falas o fato de o interesse pelas publicações, quando existente, ser referido como algo do passado, já que hoje eles as consideram inadequadas para a sua idade atual - apesar de os produtos mirarem essas idades como seu público. Como esses garotos e garotas encontram-se na fase dos tweens ${ }^{12}$, ou "pré-adolescentes", parecem querer se distanciar do que pode relacioná-los à infância, e a revista seria um desses signos. Alguns deles, inclusive, afirmaram que nunca se interessaram por esse tipo de jornalismo, pois o consideravam frívolo ou reducionista. Vejamos o que dizem dois meninos brasileiros. 0 primeiro, Paulo, de 13 anos, morador de Marília, no interior de São Paulo:

Pesquisadora: Quando você assinou a Recreio?

- Faz uns cinco anos. Lembro que eu queria assinar a Recreio. E meu irmão, meus pais assinavam a Superinteressante ${ }^{13}$. De vez em quando eu lia. Foi mais pelos brinquedinhos mesmo, que vinham de brinde. Acabava lendo. Tinha muita coisa que interessava para mim, que eu era criança. A Recreio é voltada para o público infantil mesmo. A gente assinou por um tempo e depois comprou mais na banca mesmo.

Pesquisadora: Foi comprando por um 'tempão'?

- A gente conseguiu completar um monte de coleção por causa disso. (...) Pesquisadora: Você gostava do que lia?

12 O termo vem de between (meio), no sentido de estar no meio da infância e da adolescência.

13 Revista sobre curiosidades culturais e científicas. 
- Tem curiosidades interessantes para crianças. Às vezes falava de algum desenho (animado) ou outro. Tinha joguinho, jogo dos sete erros, tinha xarada. Acho que antigamente também tinha piada. ${ }^{14}$

O segundo, Júnior, de 12 anos, é morador de São Paulo e diz:

Pesquisadora: E esses jornais que são específicos para crianças?

- Vi uma ou duas vezes, mas não gostei. Prefiro jornal mesmo. A Recreio fica dando notícia sobre o Ben 10 (desenho animado). Que eu quero saber sobre o Ben 10? Não tenho nenhum interesse no Ben 10.

Pesquisadora: O que você queria saber?

- Alguma coisa do mundo (...) mais surpreendente. ${ }^{15}$.

Contrariando a tendência, João, 14 anos, habitante do interior de Portugal, diz que ainda é leitor do magazine e continua achando suas reportagens interessantes:

Pesquisadora: E jornal e revista? Recebe alguma em casa? Compra alguma para você?

- Sim, mensalmente. O meu pai fez uma assinatura. Na altura fez para a minha irmã e depois perguntou se eu também queria a Visão Júnior.

Pesquisadora: Você recebe ainda?

— Sim, mensalmente.

Pesquisadora: Você gosta?

— Sim. Tem muitos factos interessantes, às vezes, coisas que não sabemos e ficamos a conhecer. ${ }^{16}$

Pensando nas duas faixas etárias, ou seja, dos nove aos 14 anos, ainda se identificou nas falas que a compra e a leitura dos produtos jornalísticos para crianças acontecia muitas vezes porque uma área de interesse dos entrevistados estava representada no magazine. Isso denota a importância da diversidade temática nesse tipo de veículo e contribui para que as representações da(s) infância(s) sejam também plurais.

14 Entrevista concedida por PAULO. Entrevista 7. (17 set. 2014). Entrevistadora: Juliana Doretto. Marília (SP, Brasil), 2014.

15 Entrevista concedida por JÚNIOR. Entrevista 8. (30 ago. 2014). Entrevistadora: Juliana Doretto. São Paulo (Brasil), 2014.

16 Entrevista concedida por JOÃO. Entrevista 9. (8 fev. 2014). Entrevistadora: Juliana Doretto.

Estremoz (Portugal), 2014. 
Pesquisadora: Você gosta de revista para a criança?

- Tenho a Recreio e a Ciência Hoje das Crianças.

Pesquisadora: Lê sempre?

- Às vezes eu acompanhava, agora não mais.

Pesquisadora: Você pedia para comprar? Via na biblioteca da escola?

- Pedia para comprar.

Pesquisadora: (...) E por quê?

- A Recreio eu lembro. Quando "tava" dando coisa de mitologia grega.

Pesquisadora: Você gosta muito disso, né?

(Responde afirmativamente) (Jonas, 10 anos, Rio de Janeiro) ${ }^{17}$

Pesquisadora: Vocês conhecem a Visão Júnior?

Várias meninas: Conheço.

Pesquisadora: Vocês gostam?

Maria: Eu gosto de ler o Factos Loucos (seção de curiosidades). São coisas interessantes. Tem coisas que nem meus pais sabem.

(Grupo de discussão com meninas de 11 anos, Sintra). ${ }^{18}$

Em outras situações, as crianças tinham acesso aos produtos jornalísticos por meio de mediações familiares, principalmente no caso de suplementos de jornais impressos diários, no Brasil:

— Tinha o Estadinho. Chegava na minha "vó". Não gostava muito, mas eu lia, porque não tinha muito livro para ler.

Pesquisadora: Você lembra o que lia?

- Tinha joguinhos e alguma coisa de cultura. Todo final, que era o que eu mais gostava, tinha história em quadrinhos, que era da Turma da Mônica. (Luísa, 12 anos, São Paulo)

Pesquisadora: Você conhece alguma revista ou jornal para criança?

— Conheço. Aquela lá..., o Estadinho.

Pesquisadora: Você lê?

- Eu lia. Meu pai me dava.

Pesquisadora: E por que parou?

17 Entrevista concedida por JONAS. Entrevista 10. (12 set. 2014). Entrevistadora: Juliana Doretto. Rio de Janeiro (Brasil), 2014.

18 Entrevistas concedidas por MARIA, JULIANA e CARLOTA. Grupo focal 2. (12 mar. 2014).

Entrevistadora: Juliana Doretto. Sintra (Portugal), 2014. 
— Não sei. Ele nunca mais me deu. (Luana, 11 anos, São Paulo). ${ }^{19}$

Em todos os casos, tanto no das crianças mais jovens quanto no das mais velhas, a leitura de veículos informativos para crianças é ou era sempre feita no veículo em papel. O site da publicação não foi citado pelos entrevistados, ou, quando o foi, vinha descrito como algo inferior à revista, com menos informações que as oferecidas pela publicação. Páginas on-line autônomas direcionados para o público infantil também não apareceram nas conversas. Apenas uma menina brasileira, Daniela, de 11 anos, contou sobre sua experiência on-line, apesar de não se lembrar do que tinha visto: "Os jornais na TV são mais para adultos. Eu já vi jornal de criança na internet. ${ }^{20}$

Pesquisadora: Conhece a Visão Júnior?

- Eu lia, às vezes comprava. Mas não é uma coisa que eu costumava comprar. Pesquisadora: Você gostava?

- Gostava. Tinha uns artigos que ensinavam a fazer coisas. A parte de ciências. Não sei ainda se tem. Gostava de ver o efeito. Ainda hoje vejo no YouTube (vídeos assim).

Pesquisadora: Via na internet?

— Não. Tem de fazer subscrição. E eu não tenho aplicações pagas no meu tablet. (Patrício, 12 anos, Lisboa). ${ }^{21}$

Ou seja, apesar de haver um aumento crescente do acesso das crianças às tecnologias on-line e, também, do investimento das publicações em seus suportes digitais, os leitores ainda mantêm uma ligação ao suporte papel, expressa, por exemplo, pelo não descarte dos exemplares, formando uma "coleção".

Pesquisadora: Sabe aquelas revistas para crianças como a Visão Júnior? Você já chegou

a ler?

- (...) Já tinha assim uma coleção de Visão Júnior.

Pesquisadora: É? Você comprava?

19 Entrevista concedida por LUANA. Entrevista 11. (19 ago. 2014). Entrevistadora: Juliana Doretto. São Paulo (Brasil), 2014.

20 Entrevista concedida por DANIELA. Grupo focal 3. (1 out. 2014). Entrevistadora: Juliana Doretto. São Paulo (Brasil), 2014.

21 Entrevista concedida por PATRÍCIO. Entrevista 12. (8 dez. 2013). Entrevistadora: Juliana Doretto. Lisboa (Portugal), 2013. 
- Sim.

Pesquisadora: E por que é que parou de comprar?

- Porque era júnior (ri-se) e deixou de ser assim também do meu interesse.

Pesquisadora: Do que é que você gostava?

- Eu gostava principalmente dos textos sobre os filmes e os livros e isso. (Ricardo, 13 anos, Lisboa). ${ }^{22}$

Em duas situações, em Portugal, os entrevistados não apenas liam esporadicamente a revista como também já tinham aparecido em suas páginas, como entrevistados. Essa forma de participação, no entanto, não fez aumentar nessas crianças o mediano interesse que elas tinham pelo magazine. Um dos garotos não concordou com as falas que foram atribuídas a ele pela Visão Júnior, mas isso não fez que ele reclamasse com a redação pela imprecisão. Por outro lado, o erro na transcrição de sua fala não foi suficiente para fazê-lo abandonar a revista. A atração pelos temas abordados pareceu ser a maior razão para persistir na compra, ainda que eventual, do magazine.

Pesquisadora: Você assina ou compra quando gosta?

- Compro. Tinha uma professora na minha escola antiga que aparecia, que trabalhava para a Visão Júnior, por isso eu apareci na Visão Júnior.

Pesquisadora: Quando você apareceu?

- Janeiro de 2012.

Pesquisadora: Por que você apareceu?

Para falar sobre os sonhos, no Falatório (seção da revista que reúne falas de crianças). (...)

Pesquisadora: Gostou do jeito que saiu?

- Acho que foi um bocado aldrabado.

Pesquisadora: Por quê?

— Porque não disse bem aquilo...

Pesquisadora: Eles mudaram o que você disse?

- Mais ou menos.

Pesquisadora: O que você disse exatamente e o que eles colocaram na revista?

- Colocaram que eu sonhava em ser desportista e coisas assim.

Pesquisadora: E você não disse isso?

- Não.

22 Entrevista concedida por RICARDO. Entrevista 13. (1 fev. 2014). Entrevistadora: Juliana Doretto. Lisboa (Portugal), 2014. 
Pesquisadora: O que você tinha dito?

— Disse que não sabia o que sonhava, sobre coisas que tinham acontecido no dia, principalmente.

Pesquisadora: Você reclamou com a revista?

— Não, também achei que não fazia mal.

Pesquisadora: Continuou a ler a revista mesmo assim?

— Sim. (Vagner, 11 anos, Lisboa). ${ }^{23}$

Entre os possíveis ex-leitores, com 15 e 16 anos, em Portugal, a Visão Júnior era conhecida apenas por uma garota de 15 anos, habitante de Estremoz, que a lia ocasionalmente, e não demonstrou ter tido ligação duradoura com a revista. Outra entrevistada, de 15 anos, de Lisboa, e também as de 16 anos que participaram do grupo de discussão, na zona de Sintra, afirmaram que liam a Bravo, uma revista para garotas adolescentes focada principalmente em celebridades juvenis. Já os rapazes dessa faixa etária, em Portugal, demonstraram desinteresse pelas duas publicações:

Hélio: A Júnior e a Bravo podem se juntar e podem ir embora.

Pesquisadora: Por que vocês não gostavam?

Hélio: Essas coisas nunca me cultivaram.

Gabriel: Falhavam nos nossos interesses.

Pesquisadora: De que os meninos "mais pequenos" (menores) gostam, vocês acham?

Plínio: Jogos.

António: Não é fofoquices.

(Grupo de discussão com meninos de 16 anos, Sintra). ${ }^{24}$

Um caso que chama a atenção é o fato de Mateus, 15 anos, de Lisboa, que não é leitor da Visão Júnior, ter recebido em seu e-mail notícias vindas da Ciência Hoje, publicação do mesmo instituto responsável pela $\mathrm{CHC}$, voltada ao público adulto (ou, talvez, fossem textos produzidos pela Ciência Hoje das Crianças, e o entrevistado não soube identificá-los). Pela fala do garoto, nota-se o seu desconhecimento da origem da informação:

23 Entrevista concedida por VAGNER. Entrevista 14. (26 fev. 2014). Entrevistadora: Juliana Doretto. Lisboa (Portugal), 2014.

24 Entrevistas concedidas por HÉLIO, GABRIEL, PLÍNIO e ANTÓNIO. Grupo focal 4. (13 fev. 2014). Entrevistadora: Juliana Doretto. Lisboa (Portugal), 2014. 
- (Acompanho) Em geral, desporto, notícias sobre desporto. E de ciência também, agora lembrei-me.

Pesquisadora: Ah é? Como é que funciona isso, você gosta de acompanhar? - Sim.

Pesquisadora: E... Notícias mesmo, texto sobre informação, tem algum que lembre?

— Sim, chama-se Ciência Hoje.

Pesquisadora: É brasileiro?

— Não, acho que é português.

Pesquisadora: Ah, tem um brasileiro que se chama Ciência Hoje.

- Ah, então se calhar é brasileiro.

Pesquisadora: Pode ser .pt , .com ou .br? Não dá para saber?

- Não sei, não sei, é porque eu não vou ao site, eles mandam e-mail.

Pesquisadora: Você acede?

- A subscrição.

Pesquisadora: Por e-mail ou pelo Facebook?

- Por e-mail.

Pesquisadora: (...) Vem todas as semanas ou todos os dias?

- Vinha, mas agora deixei de receber, e eu descobri, acho que foi para outro sítio no e-mail. Por isso eu deixei de acompanhar. ${ }^{25}$

Já no Brasil, os três entrevistados em conversas com jovens de 15 ou 16 anos conheciam as revistas $\mathrm{CHC}$ ou Recreio e eram leitores frequentes. Sobre a primeira delas, uma adolescente de 16 anos, Cecília, de São Paulo, mostrou ter deixado de ler o magazine por influência das amigas que tinha na época:

- (...) Eu lia a CHC. Eu adorava. Tive assinatura por muito tempo.

Pesquisadora: Você gostava?

- Eu me divertia, achava incrível. Tipo "por que cheiro de terra molhada é bom?". Achava incrível. Também negligenciava. Era idiota. Tinha acabado de ganhar o Messenger: "Não, agora eu vou falar com as minhas amigas que eu não vejo faz muito tempo, ler Harry Potter pela 30 vez".

Pesquisadora: Você passou a achar que a Ciência Hoje das Crianças era muito para crianças?

- Mais ou menos. Porque a Ciência Hoje das Crianças não te deixava, quando isso era uma preocupação, falar com as outras pessoas: "Mas sabe por

25 Entrevista concedida por MATEUS. Entrevista 15. (26 jan. 2014). Entrevistadora: Juliana Doretto. Lisboa (Portugal), 2014. 
que as plantas...?" São as meninas com quem eu parei de andar (no sentido de que elas não iam gostar das conversas).

Pesquisadora: E você gostava da Folhinha?

- Gostava, mas é que eu era bem pequena também. Mas eu paro para pensar hoje e acho que não informa as crianças sobre o que está acontecendo necessariamente. É tipo peça de teatro, quadrinhos. É a imagem que ficou. Não era um jornal com informação do mundo real para crianças. Era tipo "Você é criança. Vamos discutir o novo show da Palavra Cantada126" (...)

Acho que seria muito "da hora" se tivesse um jornal para crianças menores que fosse explicando, mesmo que fosse digerida, mesmo que fosse mais geral, sobre o que "tá" acontecendo ${ }^{27}$.

\section{'DÁ VERGONHA': A AUTOIMAGEM COMO LIMITADOR DA PARTICIPAÇÃO}

Para examinar a interação dos entrevistados com essa produção noticiosa, vamos começar por aqueles que estão incluídos nas faixas etáriasalvo das publicações escolhidas neste trabalho. $\mathrm{O}$ caso que mais se destaca é o de João, de 14 anos, do interior português, e que é leitor constante (assinante, inclusive) da Visão Júnior. O “Correio dos Leitores", espaço de publicações de cartas enviadas pelo público, foi a primeira lembrança sobre o conteúdo da revista que ele trouxe à entrevista. "É bom ver o que as outras pensam e o que nós pensamos e contrastar as ideias" ${ }^{28}$. João também nos contou a relação de seus pares com a publicação:

Pesquisadora: E do que é que você mais gosta na Visão Júnior?

- Ah... Gosto de saber a opinião dos leitores, logo no princípio. Fazem é muitas reportagens sobre ciências.

Pesquisadora: Você gosta?

- Não.

Pesquisadora: Não?

- Gosto é quando fazem reportagens assim sobre o porquê é que estamos na crise, porque é que temos a dívida... Gosto é de saber é assim essas reportagens. Também tem uma página que é assim só dos países. No final há o que os meus colegas mais gostam, que é as anedotas. Tem sempre entrevista com alguém. Também é interessante. E sempre as ideias que dão. Ainda agora recebi.

26 Dupla que se dedica à produção de músicas para crianças, no Brasil.

27 Entrevista concedida por CECÍLIA. Entrevista 16. (3 set. 2014). Entrevistadora: Juliana Doretto. São Paulo (Brasil), 2014.

28 Entrevista concedida por JOÃO. Entrevista 8. (8 fev. 2014). Entrevistadora: Juliana Doretto.

Estremoz (Portugal), 2014. 
Fevereiro já recebi, a deste mês, e estão lá uma data de partidas (brincadeiras) para fazermos no Carnaval. (...) E também tem outras coisas, a Visão Júnior. Para além de tudo isto tem sempre mais reportagens, ou sobre desporto, ou sobre os acontecimentos que vai haver durante o mês.

Pesquisadora: Você disse que gosta da opinião dos leitores, do "Correio dos Leitores". Por quê? É legal? Ver a opinião dos outros? Por que se interessa?

- Interessa é... Eles às vezes dão a opinião sobre a revista deles, fatos interessantes que acharam durante a revista toda. É bom ver o que as outras pensam e o que nós pensamos e

contrastar as ideias.

Pesquisadora: Você já chegou a escrever cartas para lá?

- Não.

Pesquisadora: Por quê?

- Não, tenho vergonha.

Pesquisadora: Tem vergonha? Júnior. ${ }^{29}$

- Não gostava de ver assim uma mensagem minha escrita na Visão

João demonstrou estar preocupado com o cenário de seu país à época, em crise econômica e com dívidas com o Fundo Monetário Internacional e instituições europeias, e conseguia, por meio da Visão Júnior, informar-se mais sobre os problemas econômicos. Mas o magazine também o satisfazia com entrevistas, notícias sobre esporte e sugestões de brincadeiras. Apesar da leitura habitual da revista e do apreço não só pelas reportagens, mas também pela opinião dos outros leitores publicada nas páginas iniciais, o garoto ouvido não demonstra interesse por escrever à Visão Júnior. Em seu relato, ao falar da vergonha em aparecer nas páginas da publicação, ele demonstra ter preocupação com a autoimagem. Morador de uma cidade pequena, o garoto ouvido não faz uso intenso das tecnologias digitais móveis, já que seus amigos vivem próximos a ele, e entre suas atividades não escolares destacam-se ações presenciais, como esportes e aulas de música. No entanto, não é a utilização frequente da internet que determina a sua falta de comunicação com a revista, mas sim a sua reserva quanto à divulgação pública de sua opinião (que, entendemos, faz parte também de sua imagem).

29 Entrevista concedida por JOÃO. Entrevista 8. (8 fev. 2014). Entrevistadora: Juliana Doretto. Estremoz (Portugal), 2014. 
Situação semelhante ocorreu com Beatriz, garota de 15 anos, também do interior português, que foi leitora ocasional da revista Visão Júnior. Vejamos trecho da entrevista:

Pesquisadora: Você já se correspondeu com algum jornal, revista ou site? Já comentou algum texto de internet? Leu alguma notícia ou algum texto que te interessava e...

- Leio e calo-me.

Pesquisadora: Por quê?

— Não sei.

Pesquisadora: Não dá vontade?

- (Pausa) Às vezes dá, mas... Acho esquisito.

Pesquisadora: É? Por quê? Esquisito?

- (Pausa) Não sei...

Pesquisadora: Dá vergonha?

- Sim, alguma.

Pesquisadora: Acha chato ficar...

- Depois não sei como é que hei de escrever, e o que é que hei de dizer. $\mathrm{E}$ ao menos se tiver a pensar depois não consigo passar para... ${ }^{30}$

Frequente utilizadora de redes sociais, a menina verificou mensagens em seu celular constantemente, mesmo durante a entrevista. Apesar da sua exposição contínua ao grupo de amigos on-line, a experiência de se expressar para um público desconhecido a assustava, e ela se considerava incapaz até de redigir seu pensamento, apesar de fazê-lo, utilizando a escrita, diversas vezes por dia, por meio de mensagens: "(...) não sei como é que hei de escrever, e o que é que hei de dizer. E ao menos se tiver a pensar depois não consigo passar para... (...)"..31

No Brasil, a "vergonha", nominalmente, foi citada por outros ex-leitores, adolescentes de16anos,comorazãoparanãoexporaopiniãoemsitesinformativos ou para não enviar correspondência a produtos jornalísticos. O primeiro, Jânio, vive no Rio de Janeiro, é um usuário frequente de aparatos tecnológicos, além de ser bastante interessado no universo noticioso. Ex-leitor da revista Recreio e hoje acompanhando, além dos telejornais, o magazine Superinteressante, ele diz, sobre possíveis comentários enviados a produtos jornalísticos:

30 Entrevista concedida por BEATRIZ. Entrevista 17. (8 fev. 2014). Entrevistadora: Juliana Doretto. Estremoz (Portugal), 2014.

31 Entrevista concedida por BEATRIZ. Entrevista 17. (8 fev. 2014). Entrevistadora: Juliana Doretto. Estremoz (Portugal), 2014 
— Não me envolvo muito.

Pesquisadora: Sabe me dizer por quê?

— Não sei se é por vergonha, alguma coisa assim. Não acho que eu preciso me envolver, não é uma coisa que eu quero. ${ }^{32}$

A segunda, Cecília, de São Paulo, ex-leitora da Ciência Hoje das Crianças e hoje bastante preocupada em não ser "completamente alienada das coisas (que se passam no mundo)" explicou:

Pesquisadora: Chegou a mandar alguma carta ou e-mail...?

- Não, mas eu sempre tive muita vergonha, muita ansiedade tipo social na vida. Então eu nunca mandei, mas tinha vontade. Às vezes, de perguntar coisas, mas mais "pra" Ciência Hoje das Crianças. Mas nunca mandei.

Pesquisadora: Foi vergonha ou também preguiça?

- Mais vergonha do que preguiça. Quando eu tinha 11 anos eu não tinha preguiça de nada. Pesquisadora: Hoje você manda ou mandaria um comentário?

- Eu discuto com meus amigos. Mas comentar em sites, tipo fóruns online, nem curto, nem acho que seja a vibe (vibração). ${ }^{33}$

Natália, leitora portuguesa da Bravo, de 15 anos, também já referida na seção anterior, chegou a se comunicar com a revista, em defesa de seu ídolo, Justin Bieber. Trata-se novamente da preocupação com a imagem, desta vez a de um outro, mas que está atrelada à de si própria: as fãs do cantor entrevistadas mostram-se preocupadas quando ele, em seu entendimento, é julgado de modo negativo.

- Por exemplo, quando postam notícias sobre qualquer coisa e eu não estou de acordo ou ... quando eu "tou" de acordo não digo nada, deixo só o texto, pronto, mas quando não estou de acordo, às vezes... assim, de vez em quando, quando me revolta mesmo eu ...

Pesquisadora: Num site por exemplo?

— Sim, no site já também, já respondi a alguns...

Pesquisadora: E, em geral, site sobre Justin ou alguma coisa assim?

- Sim.

Pesquisadora: E aí o que aconteceu?

32 Entrevista concedida por JÂNIO. Entrevista 18. (12 set. 2014). Entrevistadora: Juliana Doretto. Rio de Janeiro (Brasil), 2014.

33 Entrevista concedida por CECÍLIA. Entrevista 16. (3 set. 2014). Entrevistadora: Juliana Doretto. São Paulo (Brasil), 2014. 
—É que normalmente os sites que falam do Justin são... quando alguém posta a falar dele no Facebook e eu não concordo, eu comento, quando há sites mesmo verdadeiros, revistas, sites de rádio ou isso, eu mando... tipo, tenho que mandar mail, né, porque eles não têm outra maneira (...) Mas e muitas poucas vezes, quase nunca...

Pesquisadora: Mas eles responderam quando você mandou?

- Não. ${ }^{34}$

Em outro relato, transparece a importância do estímulo do canal on-line à participação. Com 15 anos, Mateus, de Lisboa, apesar de não ser leitor da Visão Júnior, diz que gosta de fazer comentários no YouTube e em outras plataformas em que é possível deixar opinião, incluindo sites noticiosos - neste último caso, por meio de incentivos dos veículos.

— Sim, acho que é uma parte importante, porque... Vemos um vídeo, e depois as pessoas comentam, normalmente assim brincadeiras, outras vezes não, e podemos ver também a resposta que as pessoas têm aos vídeos, e isso é engraçado.

Pesquisadora: E nas notícias também isso acontece?

- Nas notícias também, tudo o que têm para comentar...

Pesquisadora: (...) Você já mandou às vezes alguma carta ou e-mail para um jornal, uma revista, um site de notícias específico?

- Talvez, talvez.

Pesquisadora: Não se lembra exatamente?

- Talvez.

Pesquisadora: Se o fizesse, seria por quê? Pedindo alguma matéria?

- Se fizesse seria a pedir ou a agradecer o trabalho. Às vezes, no fundo é isso.

Pesquisadora: Isso é simpático, mandar um e-mail agradecendo.

— Às vezes sim. Pesquisadora: Já fez isso?

- Sim, às vezes. Não é totalmente por iniciativa própria, porque às vezes eles põe lá "Ah, deem-nos um feedback", e se for um site que tem até bastante interesse eu mando um e-mail a dizer que tem qualidade e que devem continuar. $^{35}$

34 Entrevista concedida por NATÁLIA. Entrevista 19. (25 jan. 2014). Entrevistadora: Juliana Doretto. Lisboa (Portugal), 2014.

35 Entrevista concedida por MATEUS. Entrevista 15. (26 jan. 2014). Entrevistadora: Juliana Doretto. Lisboa (Portugal), 2014. 
Em outro caso, Mário, 11 anos, de São Paulo, leitor da revista Mundo Estranho (voltada a curiosidades científicas), diz que se comunicou com esse magazine tanto por conta de uma tarefa dada por um professor quanto por iniciativa própria, mas não recebeu resposta da publicação, o que não o surpreendeu:

- Mandei outra (carta) por conta própria. É e-mail que tem de mandar. Pesquisadora: Por quê?

- Alguma coisa que eu tinha lido lá e achei absurda. A Abril (editora que publica o magazine), são muito conservadores, eles escrevem umas coisas muito absurdas. Mandei reclamando, mas eles não responderam. Era óbvio que eles não iam publicar aquilo. Queria só que eles pensassem.

Pesquisadora: Por que era óbvio?

— Até parece que eles iam publicar uma reclamação. ${ }^{36}$

Outra situação, o único caso entre as crianças mais novas, envolve Cristina, de nove anos, de Marília, que enviou uma carta para a $\mathrm{CHC}$ por conta de uma atividade escolar. Como vimos anteriormente, a garota não gosta muito da revista, já que a temática da publicação não lhe atrai. Assim, ela nem mesmo se lembra do que escreveu para o magazine:

- A professora pediu "pra" gente fazer uma carta para a revista. Tem lá no fim a carta que as crianças mandam, e a revista responde. Mas acho que ela (a professora) ainda não mandou?

Pesquisadora: Você escreveu o quê?

— Já não me lembro. ${ }^{37}$

Assim, entre os adolescentes de 13 a 16 anos que se disseram leitores ocasionais ou habituais de veículos impressos para crianças, a participação nem sempre ocorreu por vergonha de terem suas opiniões expostas nas páginas dos produtos. Quando a comunicação ocorreu, ela foi gerada por discordância do que havia sido dito pela publicação, por interesse em desenvolver a carreira jornalística no futuro ou por estímulo do veículo, com pedidos de avaliações por parte dos leitores.

36 Entrevista concedida por MÁRIO. Entrevista 4. (8 set. 2014). Entrevistadora: Juliana Doretto. São Paulo (Brasil), 2014.

37 Entrevista concedida por CRISTINA. Entrevista 6. (18 set. 2014). Entrevistadora: Juliana Doretto. Marília (SP, Brasil), 2014. 
Nos discursos de jovens que não acompanharam tais publicações quando eram crianças, surgem desinteresse e apatia quando se pergunta sobre a participação na produção jornalística para o público infantil. Como eles apresentaram menor ligação com as publicações, obviamente não se comunicaram, mas não apenas com as revistas infantojuvenis: houve falta de motivação para se corresponder com a mídia em geral.

Na outra ponta, em relação às crianças mais jovens, entre 9 e 12 anos, que em geral também contaram ter pouco ou nenhum contato com as revistas, não foi relatada nenhuma participação voluntária, mas os entrevistados, nos dois países e em diversos casos, afirmaram que estariam interessados em tomar parte de concursos ou enviar mensagens se houvesse um prêmio que lhes interessasse ou se amigos participassem também.

\section{CONSIDERAÇÕES FINAIS}

Comecemos as análises dos resultados expostos aqui pelo que não se pode afirmar a partir do que foi ouvido nas entrevistas e nos grupos de discussão. Não podemos dizer que o contato com as tecnologias favorece o apreço pelo jornalismo infantojuvenil, ou ainda que estimule a comunicação das crianças e jovens com os produtores de notícia. Também não se pode concluir que o interesse das crianças e jovens pelo jornalismo infantojuvenil esteja ligado à importância que dão ao jornalismo de maneira geral.

O envolvimento com esse tipo de produção noticiosa parece na verdade estar mais relacionado a outros dois fatores: o primeiro deles é o oferecimento dos veículos jornalísticos pela família ou pela escola; o segundo é a abordagem, nas publicações, de temas que interessam aos leitores. Quando assuntos caros às crianças aparecem nas capas das revistas, quando elas estão expostas nos seus locais de venda habituais, há um interesse pela compra, que pode suscitar novas aquisições do mesmo veículo. Como consequência, podemos afirmar que quanto maior a diversidade temática nos produtos jornalísticos infantojuvenis, maior a probabilidade de atrair a curiosidade de potenciais leitores. Isso fica claro quando analisamos o cenário brasileiro: como a variedade de veículos é maior do que a de Portugal, encontramos mais leitores, ainda que esporádicos (e a maior parte deles teve contato com mais de um produto). Isso, para nós, é um indício de que as crianças desejam que as representações das infâncias sejam mais diversas do que as que hoje lhe são apresentadas. 
A partir disso, conclui-se que, assim como o mercado jornalístico para adultos oferece uma grande gama de publicações, sites e programas jornalísticos, para atender diferentes expectativas do público, o jornalismo infantojuvenil deveria também apresentar um maior cardápio temático, oferecendo aos potenciais leitores não apenas mais materiais em diferentes áreas de atração, mas também informações mais aprofundadas e críticas sobre esses variados temas. As possibilidades abertas pela internet (menos limitadas por obstáculos produtivos, como quantidade de papel ou tempo e custos de distribuição) poderiam ser uma solução interessante para esse mercado, desde que fossem desenvolvidastambém aplicaçõespara celularesouperfis em redes sociais ${ }^{38}$ como forma de divulgação desses órgãos jornalísticos. Essa afirmação vem das falas coletadas: foi comum ouvir dos meninos e meninas que acompanham notícias (ou, em vários casos, apenas informação) do seu tema de interesse por meio de aplicativos em telefones móveis ou por páginas no Facebook, o que não ocorre quando questionados se costumavam acessar sites devotados a essas temáticas.

Essa mudança poderia afetar, sobretudo, os leitores com 11 ou 12 anos de idade, que têm mais contato com celulares e tablets e o fazem com maior liberdade do que as crianças menores. Aliás, essas faixas etárias parecem ser o limite do público do jornalismo infantojuvenil, pois os tweens já fazem a transição para produtos voltados a adolescentes, por não desejarem mais serem identificados como crianças, e sim como aqueles que estão iniciando a adolescência. Entre esses garotos e garotas, houve casos em que o jornalismo para crianças nunca despertou interesse, pois sempre lhes pareceu superficial e simplório (ou "infantilizado", no mau e estigmatizado sentido da palavra), com temáticas aquém de seus interesses.

Por fim, discorremos sobre o que pode contribuir para o aumento da comunicação das crianças com os órgãos jornalísticos. As entrevistas e debates mostraram que, para que haja participação, é preciso, em primeiro lugar, que as crianças se sintam motivadas a acompanhar, com mais frequência, os veículos jornalísticos a elas destinados - o que, como vimos, está atrelado à mediação adulta e à temática abordada. Após esse passo, dois grandes obstáculos aparecem no contato mais direito entre leitores e jornalistas: a ausência de resposta por parte dos produtores de informação e a preocupação em expor-se. Enquanto o primeiro pode ser entendido também como uma vontade do leitor de exibir-se na publicação que lhe é cara, o segundo, oposto a isso, é resumido nominalmente pelas crianças como "vergonha". Essa preocupação com a

38 Ainda que o Facebook recomende que apenas crianças com no mínimo 13 anos utilizem a rede, elas estão lá. Caso o publicador decida ser prudente não investir nesse canal, há outras que podem ser alvo de investimento. 
autoimagem deve ser entendida no contexto da pressão dos pares. Pasquier (2008) entende que os mais jovens se esforçam para serem aceitos nos grupos de amigos como forma de "confirmar suas próprias identidades". (Pasquier, 2008, p. 449). Assim, evitar a exposição de sua imagem (entendendo a expressão da opinião como um elemento dessa imagem) é uma forma de escapar de ser criticado ou ridicularizado pelos pares.

Para diminuir este último obstáculo, seria importante os veículos para as crianças deixarem mais claro que a correspondência enviada não será, necessariamente, publicada, caso não seja de interesse das crianças (o que não aparece em nenhuma das duas revistas por nós estudadas). Além disso, sugerimos que investissem em canais de participação anônimos, e também mais rápidos, em seus sites e perfis em redes sociais, como votações e enquetes. Afirmamos também que a estratégia de promover concursos em busca de maior participação, como ocorre na Visão Júnior, é avaliada pelas crianças como uma forma interessante de enviar sugestões ou produções próprias (como textos e desenhos) à revista. Ainda que o interesse da criança seja ganhar um prêmio, essa pode ser uma forma indireta de os jornalistas que escrevem para os mais jovens ficarem a conhecer o que elas desejam ver nos textos por eles produzidos.

Como conclusão, nota-se a pluralidade de caminhos que levam à atenção e à dedicação da criança ao jornalismo para elas destinados. Não se trata de uma estrada direta, porém tampouco estamos falando aqui de uma recusa infantil a trilhar esse caminho. É necessário oferecer a elas um pavimento de acordo com suas capacidades. Sua própria curiosidade em percorrer a estrada é o motivador para que elas comecem a caminhar.

\section{REFERÊNCIAS}

BUCKINGHAM, David. O direito das crianças para os media. In: PONTE, Cristina. (Org.). Crianças e jovens em notícia. Lisboa: Livros Horizonte, 2009.

DIJCK, José van. The culture of conectivity. New York: Oxford University Press, 2013. GHIGLIONE, Rodolphe; MATALON, Benjamin. O Inquérito. Oeiras: Celta Editora, 2005.

KRESS, Gunther.; LEEUWEN, Theo van. Multimodal discourse: the modes and media of contemporary communication. London: Hodder, 2001.

LIVINGSTONE, Sonia; DROTNER, Kirsten. Editor's Introduction. In: The international handbook of children, media and culture. London: Sage, 2008. 
MORLEY, David. Unanswered questions in audience research. E-Compós - Revista da Associação Nacional dos Programas de Pós-Graduação em Comunicação, v. 6, p. 101-121, 2006.

PASQUIER, Dominique. From parental control to peer pressure: cultural transmission and conformism. In: LIVINGSTONE, Sonia.; DROTNER, Kirsten. (Eds.). The international handbook of children, media and culture. London: Sage, 2008.

\section{Sites consultados}

Por que a carambola tem formato de estrela? Recreio Uol. Brasil. Disponível em: http:// recreio.uol.com.br/noticias/curiosidades/por-que-a-carambola-tem-formatode-estre la.phtml. Acesso em: 14 mai. 2015.

Convenção sobre o direito das crianças. Presidência da República - Casa Civil. Brasil. Disponível em: http://www.planalto.gov.br/ccivil_03/decreto/1990-1994/d997 10.htm. Acesso em: 17 jul. 2015.

\section{Entrevistas}

BEATRIZ. Entrevista concedida a Juliana Doretto. Estremoz (Portugal), 8 fev. 2014.

CECÍLIA. Entrevista concedida a Juliana Doretto. São Paulo (Brasil), 3 set. 2014.

CRISTINA. Entrevista concedida a Juliana Doretto. Marília (SP, Brasil), 18 set. 2014.

DANIELA. Entrevista concedida a Juliana Doretto. São Paulo (Brasil), 1 out. 2014.

FÁTIMA. Entrevista concedida a Juliana Doretto. Lisboa (Portugal), 15 fev. 2014.

HÉLIO; GABRIEL; PLÍNIO; ANTÓNIO. Entrevistas concedidas a Juliana Doretto. Lisboa (Portugal), 13 fev. 2014.

JÂNIO. Entrevista concedida a Juliana Doretto. Rio de Janeiro (Brasil), 12 set. 2014.

JÚNIOR. Entrevista concedida a Juliana Doretto. São Paulo (Brasil), 30 ago. 2014.

JOÃO. Entrevista concedida a Juliana Doretto. Estremoz (Portugal), 8 fev. 2014.

JONAS. Entrevista concedida a Juliana Doretto. Rio de Janeiro (Brasil), 12 set. 2014.

LAURA. Entrevista concedida a Juliana Doretto. Marília (SP, Brasil), 19 set. 2014.

LUANA. Entrevista concedida a Juliana Doretto. São Paulo (Brasil), 19 ago. 2014.

LUCAS; JORGE; RENATO. Entrevistas concedidas a Juliana Doretto. São Paulo (Brasil), 1 out. 2014. 
MARIA; JULIANA; CARLOTA. Entrevistas concedidas a Juliana Doretto. Sintra (Portugal), 12 mar. 2014.

MÔNICA. Entrevista concedida a Juliana Doretto. Estremoz (Portugal), 8 fev. 2014.

MÁRIO. Entrevista concedida a Juliana Doretto. São Paulo (Brasil), 8 set. 2014.

MATEUS. Entrevista concedida a Juliana Doretto. Lisboa (Portugal), 26 jan. 2014.

NATÁLIA. Entrevista concedida a Juliana Doretto. Lisboa (Portugal), 25 jan. 2014.

PATRÍCIO. Entrevista concedida a Juliana Doretto. Lisboa (Portugal), 8 dez. 2013.

PAULA. Entrevista concedida a Juliana Doretto. Lisboa (Portugal), 5 abr. 2014.

PAULO. Entrevista concedida a Juliana Doretto. Marília (SP, Brasil), 17 set. 2014.

RICARDO. Entrevista concedida a Juliana Doretto. Lisboa (Portugal), 1 fev. 2014.

VAGNER. Entrevista concedida a Juliana Doretto. Lisboa (Portugal), 26 fev. 2014.

Recebido em: 1/5/2017

Aceito em: 29/5/2017

Dados da autora:

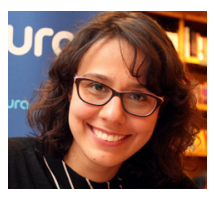

Juliana Doretto |jdoretto@gmail.com

Doutora em Ciências da Comunicação pela Universidade Nova de Lisboa e professora do Programa de Mestrado Profissional em Jornalismo do Fiam-Faam Centro Universitário, São Paulo.

Programa de Mestrado Profissional em Jornalismo do Centro Universitário Fiam-Faam

Avenida Liberdade, $749-7^{\circ}$ andar

01503-001 - São Paulo (SP) - Brasil 